\title{
Evaluation of mobility and stability in the Discover artificial disc: an in vivo motion study using high-accuracy 3D CT data
}

\author{
Martin Skeppholm, MD, PhD, ${ }^{1,2}$ Per Svedmark, MD, PhD, ${ }^{1,2}$ Marilyn E. Noz, PhD, ${ }^{3}$ \\ Gerald Q. Maguire Jr., PhD, ${ }^{4}$ Henrik Olivecrona, MD, PhD, ${ }^{2}$ and Claes Olerud, MD, PhD ${ }^{5}$
}

'Stockholm Spine Center, Löwenströmska Sjukhuset, Upplands Väsby; ${ }^{2}$ Department of Molecular Medicine and Surgery, Karolinska Institute, Stockholm; ' 4 School of Information and Communication Technology, KTH, Royal Institute of Technology, Kista; ${ }^{5}$ Department of Orthopedic Surgery, Uppsala University Hospital, Uppsala, Sweden; and ${ }^{3}$ Department of Radiology, New York University School of Medicine, New York, New York

OBJECT Artificial disc replacement (ADR) devices are unlike implants used in cervical fusion in that they are continuously exposed to stress not only within the implant site but also at their site of attachment to the adjacent vertebra. An imaging technique with higher accuracy than plain radiography and with the possibility of 3D visualization would provide more detailed information about the motion quality and stability of the implant in relation to the vertebrae. Such high-accuracy studies have previously been conducted with radiostereometric analysis (RSA), which requires implantation of tantalum markers in the adjacent vertebrae. The aim of this study was to evaluate in vivo motion and stability of implanted artificial discs. A noninvasive analysis was performed with CT, with an accuracy higher than that of plain radiographs and almost as high as $\mathrm{RSA}$ in cervical spine.

METHODS Twenty-eight patients with ADR were included from a larger cohort of a randomized controlled trial comparing treatment of cervical radiculopathy with ADR or anterior cervical decompression and fusion. Surgical levels included C4-7; 18 patients had 1-level surgery and 10 patients had 2-level surgery. Follow-up time ranged from 19 to 50 months, with an average of 40 months. Two CT volumes of the cervical spine, 1 in flexion and 1 in extension, were obtained in each patient and then spatially registered using a customized imaging tool, previously used and validated for the cervical spine. Motion between the components in the artificial disc, as well as motion between the components and adjacent vertebrae, were calculated in 3 planes. Intraclass correlation (ICC) between independent observers and repeatability of the method were also calculated.

RESULTS Intrinsic motion, expressed as degrees in rotation and millimeters in translation, was detectable in a majority of the ADRs. In the sagittal plane, in which the flexion/extension was performed, sagittal rotation ranged between $0.2^{\circ}$ and $15.8^{\circ}$ and translation between 0.0 and $5.5 \mathrm{~mm}$. Eight percent of the ADRs were classified as unstable, as motion between at least 1 of the components and the adjacent vertebra was detected. Five percent were classified as ankylotic, with no detectable motion, and another $8 \%$ showed very limited motion due to heterotopic ossification. Repeatability for the motion in the sagittal plane was calculated to be $1.30^{\circ}$ for rotation and $1.29 \mathrm{~mm}$ for translation $(95 \%$ confidence level), ICC 0.99 and 0.84, respectively. All 3 patients with unstable devices had undergone 1-level ADRs at C5-6. They all underwent revision surgery due to increased neck pain, and instability was established during the surgery.

CONCLUSIONS The majority of the artificial discs in this study showed intrinsic mobility several years after implantation and were also shown to be properly attached. Implant instability was detected in $8 \%$ of patients and, as all of these patients underwent revision surgery due to increasing neck pain, this might be a more serious problem than heterotopic bone formation.

Clinical trial registration no.: ISRCTN44347115 (www.ISRCTN.com)

http://thejns.org/doi/abs/10.3171/2014.12.SPINE14813

KEY WORDS artificial disc replacement; mobility; computed tomography; instability; revision surgery

ABBREVIATIONS ADR = artificial disc replacement; $\mathrm{HA}=$ hydroxyapatite; $\mathrm{HO}$ = heterotopic ossification; $\mathrm{ICC}=$ intraclass correlation; $\mathrm{NDI}=$ neck disability index; $\mathrm{RCT}$ = randomized controlled trial; $\mathrm{ROM}=$ range of motion; $\mathrm{RSA}=$ radiostereometric analysis.

SUBMITTED August 19, 2014. ACCEPTED December 30, 2014

INCLUDE WHEN CITING Published online June 5, 2015; DOI: 10.3171/2014.12.SPINE14813.

DISCLOSURE Clinical and research support for this study was provided by DePuy Spine, Stockholm Läns Landsting, and the Swedish Society for Spine Surgeons. 
$\mathrm{W}$ ITH the introduction and increased use of artificial disc replacement (ADR) during the last 2 decades there is also a need to evaluate and understand how these implants behave in vivo, in terms of both motion and stability. Focus in previous studies has been on motion within the discs and heterotopic ossification (HO) surrounding the discs, while there is very limited knowledge about stability of the implants and how different techniques for anchoring the devices affect this. The aim of this study was to evaluate range of motion (ROM) and stability in the Discover artificial disc (DePuy Spine) segments using a 3D CT method previously validated for cervical spine by Svedmark and colleagues. The method has the capability to measure motion both within the implant and relative to the adjacent bone with an accuracy that has been previously established. ${ }^{30,31}$ Previous studies on spinal mobility have been performed with varying accuracy, depending on the technique used. , $^{12,14,19-23,28,37,40}$ Radiostereometric analysis (RSA) has been shown to be the most accurate; $1,26,27$ however, the technique always requires implantation of tantalum markers and is therefore an invasive method. The accuracy is also dependent on how the markers are distributed within the vertebrae. The technique that we have used is noninvasive and therefore easier to use than RSA in clinical practice. In this study, we also took the opportunity to test repeatability between 2 different observers.

\section{Methods}

The patients in this study were all recruited from a larger multicenter randomized controlled trial (RCT) comparing reconstruction with anterior cervical decompression and fusion and ADR. The RCT was registered with the ISRCTN registry (www.ISRCTN.com), and its registration number is ISRCTN44347115. The primary outcome variable in the RCT was the neck disability index (NDI), with scores collected preoperatively and 2 years after surgery. Twenty-eight patients were included. Informed consent was obtained from all patients, and the study was approved by the regional ethics committee in Stockholm. These 28 patients accounted for $35 \%$ of all those patients in the RCT who were treated with ADR, and they were selected on the basis of living in the Stockholm area, with easy access to the examining clinic. Sixteen $(57 \%)$ were women, and the average age was 46.6 years (range 3757 years). All investigations were performed at the same clinic (Aleris, Löwenströmska Hospital, Sweden), with a standard procedure described in detail below. Surgery was performed by 4 surgeons, using a standard anterior approach, with decompression of affected nerve tissue, including resection of the posterior longitudinal ligament. All of the patients were given $25 \mathrm{mg}$ of diclofenac 3 times a day orally for 10 days after surgery, with the intention of minimizing the formation of heterotopic bone around the prostheses. The distribution of surgical levels at the time of CT scan is shown in Table 1. The mean time between surgery and CT scanning was 40 months (range 19-50 months). The Discover artificial disc was used in all patients randomized to ADR. The Discover disc does not have an FDA approval and is not available for commercial
TABLE 1. Distribution of surgical levels and mean rotation in the sagittal plane*

\begin{tabular}{ccccc}
\hline & & \multicolumn{3}{c}{ Mean Sagittal } \\
Level & 1-Level ADR & 2-Level ADR & Rotation & Range (SD) \\
\hline C4-5 & 2 & 0 & 6.7 & $6.5-7.0(0.4)$ \\
\hline C5-6 & 10 & 10 & 6.2 & $1.0-15.8(4.1)$ \\
\hline C6-7 & 6 & 10 & 3.0 & $0.2-6.0(2.4)$ \\
\hline
\end{tabular}

* All values are degrees.

use in the United States. The device is an unconstrained ball and socket construction consisting of 3 parts -2 titanium endplates with a half sphere of polyethylene fixed in the caudal section. Six small spikes impacted into the vertebral endplates provide primary stability. The contact surface is also coated with hydroxyapatite (HA) to promote ingrowth of bone and fixation. Two CT scans of each patient were obtained with the patients placed in the CT scanner on their left side at a $90^{\circ}$ angle to the supine position, and their head supported by a stiff pillow. With this support for the head, it was possible to adjust the position so that the cervical spine was in a neutral position before scanning. This position was chosen after a number of trials in the supine position, in which flexion and extension required more force due to restriction of the head and neck support. Lying on their side, patients could easily move their head into maximal flexion and maximal extension. A CT scan was obtained in each position, creating a "flexion CT volume" and an "extension CT volume." The CT scans were obtained with a Somatom Definition AS clinical scanner (Siemens) using a standard clinical low-dose protocol. The radiation dose was calculated to be $0.33 \mathrm{mSv}$ per scan. Slices were reconstructed at $0.6-\mathrm{mm}$ increments, which was different from the study by Svedmark, where slices were reconstructed at $1 \mathrm{~mm}$. All image analysis was performed using a 3D volume fusion (spatial registration) tool, which has been previously described. ${ }^{30} \mathrm{Hav}$ ing validated accuracy (Table 2), this semiautomated tool provides landmark-based fusion of 2 volumes, registering the flexion CT volume with the extension CT volume via a variety of 3D transform modules, from simple rigid body, to 3D warping, to user defined. The computer's 2D pointing device was used to specify landmarks on isosurfaces, with the software automatically finding the corresponding $3 \mathrm{D}$ points. A technical description can be found in previous publications. ${ }^{16,17}$

The kinematics analysis measured 2 motions: 1) movement of the prosthetic lower component relative to the upper component and 2) movement between any of the components of the ADR and the attaching vertebrae. The procedure for each requires manually selecting a small number of landmarks (Fig. 1) on isosurfaces, followed by the automatic calculation of the desired movement by the image analysis tool. For more detailed information on this method, please see the previous studies by Svedmark and colleagues. ${ }^{30-32}$ If no motion between the lower and upper prosthetic component could be detected, the segment was classified as ankylotic. If there was any detectable motion between any of the prosthetic components and the vertebrae to which they were attached, it was classified as an 
TABLE 2. Accuracy of 3D CT in all 3 planes

\begin{tabular}{ccc}
\hline Plane & Rotation $\left(^{\circ}\right)$ & Translation $(\mathrm{mm})$ \\
\hline Sagittal & 0.7 & 0.4 \\
\hline Coronal & 0.4 & 0.2 \\
\hline Transaxial & 0.2 & 0.5 \\
\hline
\end{tabular}

unstable or loose device. To evaluate the interobserver repeatability, 2 observers independently analyzed all patient volumes. A total of 38 prostheses were analyzed, as 10 patients had 2-level ADRs.

\section{Statistics}

ROM within each implant is presented as mean values with standard deviations (SDs); rotation is measured in degrees and translation in millimeters. The Fisher exact test was used to compare motion between the different levels. A Student t-test for independent samples was used to compare motion between the caudal and the apical prostheses in the group of patients with 2-level ADR. A 95\% CI was calculated with the Wilson quadratic method for the possibility of loosening or ankylosis of the prosthesis. ${ }^{6}$ Intraclass correlation (ICC) was calculated between the 2 observers for all 28 patients, 38 prostheses in total. ICC was considered good if Cohen's kappa coefficient was $>$ 0.61 and very good if it was $>0.80 .{ }^{8}$ The standard error of measurement was calculated and is generally highly associated with the reliability coefficient, kappa, and may be more informative about the range within which the true value is most likely to fall. Repeatability was calculated with a $95 \%$ confidence level for all motions and was defined as the maximum deviation between measurements under the same conditions and with the same measuring instrument. Pre- and postoperative NDI values are presented as means with SDs and compared by use of the Wilcoxon signed-rank test. Statistical significance was set at a $\mathrm{p}$ value $<0.05$. Statistica software version 11 (StatSoft Inc.) was used for all calculations.

\section{Results}

All prostheses could be successfully evaluated both

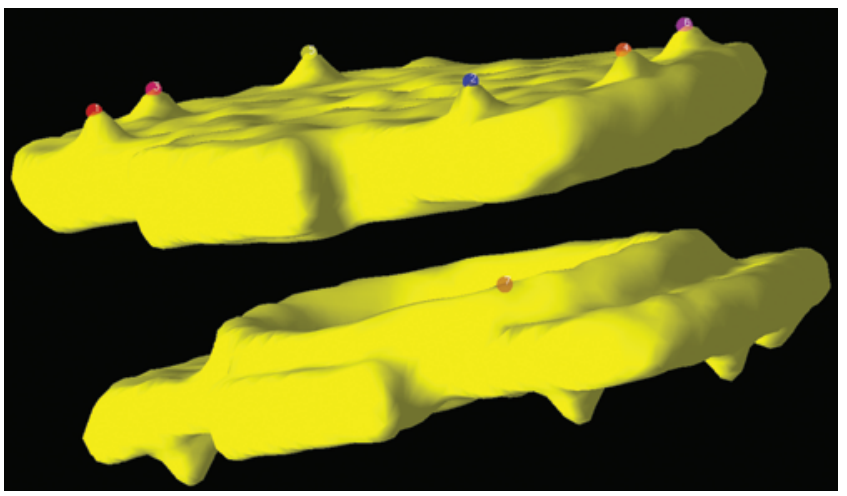

FIG. 1. Interactive 3D isosurface representation of the prosthesis. Numbered landmarks are situated on elevated pegs on the upper component. Automatically generated Landmark 7 is shown below Landmark 2 (third landmark from the right on the upper component). numerically and visually (Fig. 2). In the sagittal plane, in which the principal movement (flexion-extension) was performed, the mean rotation was $5.1^{\circ}$ (SD 3.8 $)$ with a range of $0.2^{\circ}$ to $15.8^{\circ}$, and the mean translation was 1.0 $\mathrm{mm}$ (SD $1.2 \mathrm{~mm}$ ) with a range of $0.0-5.5 \mathrm{~mm}$. The rotation and translation in the other planes were, as expected, small, and motions in all 3 planes are presented in Table 3 . There was a statistically significant difference in mean sagittal rotation, with less motion at the C6-7 level (mean $\left.3.0^{\circ}\right)$ than at the C5-6 level (mean 6.2 $)(\mathrm{p}<0.01$, Table 1). No significant difference could be seen between the C4-5 level and the other levels. The mean rotation in the single-level ADR group was 5.7 $\left(\mathrm{SD} 4.1^{\circ}\right)$. In the 2-level ADR group, the mean rotations in the caudal and the apical ADRs were $3.3^{\circ}\left(\mathrm{SD} 2.7^{\circ}\right)$ and $5.7^{\circ}\left(\mathrm{SD} \mathrm{3.9^{ \circ }}\right)$, respectively. The difference was not statistically significant $(\mathrm{p}=$ 0.08 ). When motion was compared between 1- and 2-level surgeries altogether, no statistically significant difference was found $(\mathrm{p}=0.52)$. The mean NDI score in this cohort changed from 64 (SD 16.7) preoperatively to 40 (SD 20.7) at 2-year follow-up $(\mathrm{p}=0.01)$.

Evaluation of the registered volumes showed that in 2 prostheses (5\%) there was a clear ankylosis with bridging bone around the ADR and no detectable motion. Three other prostheses $(8 \%)$ had bone masses that bridged the operated segment but had detectable motion and were therefore not classified as ankylotic. One of these prostheses was the lower level of a 2-level replacement with a fused upper level, and 2 of them were 1-level disc replacements. The probability for ankylosis was calculated to be between $1 \%$ and $17 \%(95 \% \mathrm{CI})$. In $3(8 \%)$ of the devices there was a detectable motion between a component of the ADR and the bone. There was also osteolysis in conjunction with the loose prosthetic component in 2 of these (Fig. 3). The probability for loosening was calculated to be between $3 \%$ and $21 \%(95 \% \mathrm{CI})$. All loose components were detected in the 1-level group and at the C5-6 level. In all of these cases, it was the upper component of the prosthesis that showed motion in relation to the vertebra. Additionally, there was osteolysis in conjunction with 1 more apical component, without detectable motion between the bone and component (Fig. 4). The relative measured movement between the loose components and

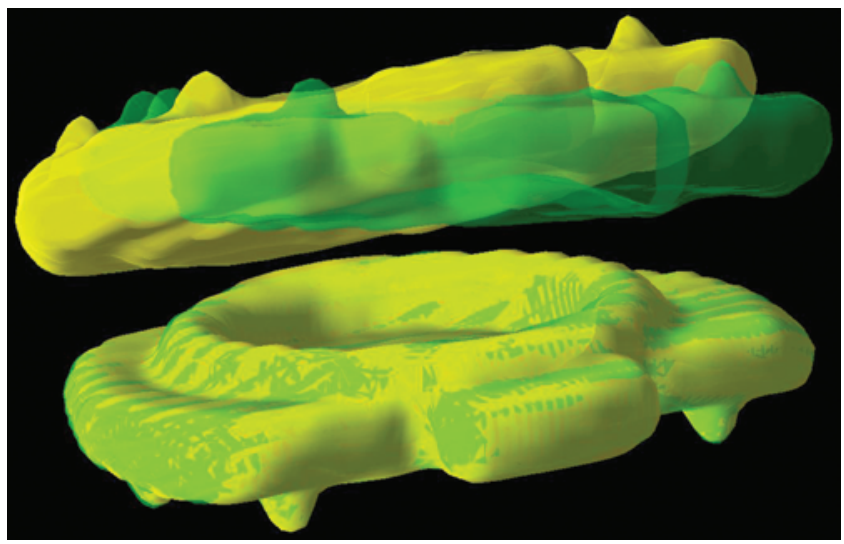

FIG. 2. Visual presentation of 3D motion. The lower component is a "fusion" of the 2 CT volumes, and the upper image depicts motion in flexion (green) and in extension (yellow). 
TABLE 3. Measured motion in all 3 planes for all prosthetic levels

\begin{tabular}{ccc}
\hline Motion & Mean (SD) & Range \\
\hline Rotation in degrees & & \\
\hline Coronal & $1.4(1.5)$ & $0.0-5.5$ \\
\hline Sagittal & $5.1(3.8)$ & $0.2-15.8$ \\
\hline Transaxial & $1.4(1.5)$ & $0.0-6.2$ \\
\hline Translation in mm & & \\
\hline Coronal & $0.2(0.2)$ & $0.0-0.8$ \\
\hline Sagittal & $1.0(1.2)$ & $0.0-5.5$ \\
Transaxial & $0.9(0.8)$ & $0.0-2.7$ \\
\hline
\end{tabular}

the vertebrae is presented in Table 4. No association between ankylosis or loosening and time to follow-up could be seen. The repeatability between 2 observers in the sagittal plane was $1.3^{\circ}$ and $1.3 \mathrm{~mm}$ (95\% confidence level), and the ICC was good or very good except for translation in the coronal plane, which was classified as "fair." The ICC in the test-retest showed kappa coefficients varying between 0.30 and 0.99 (Table 5). All patients in whom instability was detected underwent later revision, where the radiological finding could be established intraoperatively, as the apical parts were not properly fixed to the adjacent vertebrae. All the lower components of the prostheses were fixed, however, and substantial force was required to remove them. As there were clear signs of bone loss in the anterior part of the upper vertebrae, the segments had to be reconstructed with cages, and in 1 patient this resulted in a corpectomy and a 2 -level fusion to restore alignment. In 1 of the removed discs, there was also obvious wear of the polyethylene sphere.

\section{Discussion}

When studying spinal kinematics, there are several different motions that can be observed, and the biomechanics are complex. In this study, we have chosen to evaluate motion between the components of implanted prostheses and motion of the prostheses relative to the bone in voluntary extension and flexion. However, motion was measured in 3 planes, and this shows, not surprisingly, that there are de-
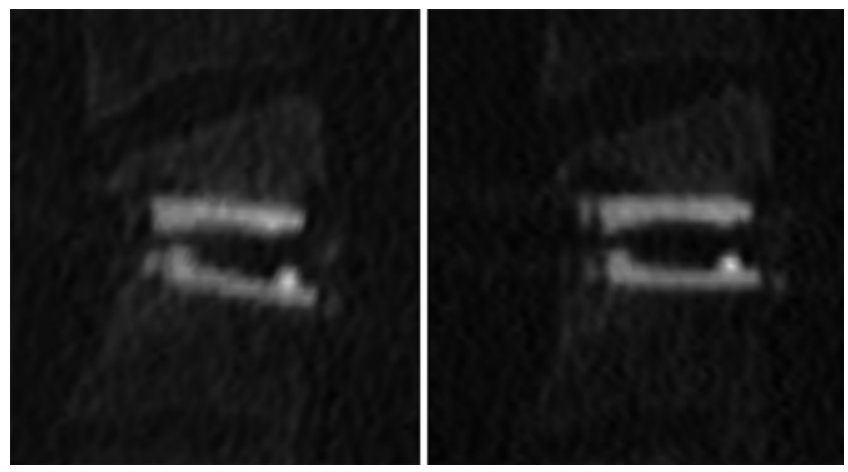

FIG. 3. CT images from Case 3 , one of the 3 cases in which osteolysis was seen in conjunction with a loose ADR component. Motion is evident between the upper component of the prosthesis and bone in both flexion (left) and extension (right). Osteolysis can be seen in the anterior part of the upper vertebrae, adjacent to the component.

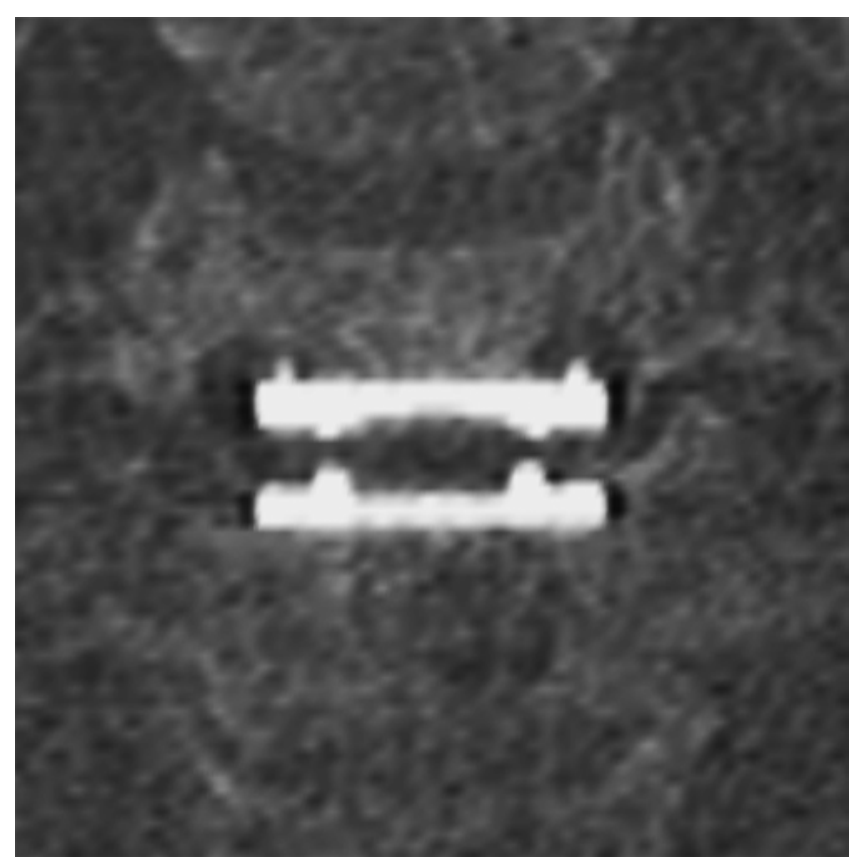

FIG. 4. CT image obtained in the patient who had osteolysis in conjunction with the more apical component without detectable motion between the bone and the component. Osteolysis can be seen around the pegs of the upper component; no movement between component and bone was observed.

tectable and coupled motions in different planes. This can be partly explained by the impossibility of achieving motion in just 1 plane in a clinical setting, and partly by the finding that motion segments do not always move symmetrically. It should also be pointed out that measurements with this technique are done only in the end positions of flexion and extension. For evaluation of the whole motion, dynamic methods are required. The accuracy of the technique used in this study has previously been evaluated and was determined to be not as good as RSA in vitro; however, it is almost as good as RSA in vivo for the cervical spine. As slice thickness in this study was thinner than in the validation study, we can assume that the accuracy might be even higher. In this study, we also added reliability tests between observers. The ICCs between observers were good for most motions but only "fair" for coronal translation. This can be explained by the fact that the ROM in most patients does not exceed the accuracy of the measurement in that plane. The ICC is very good for the motion that patients performed between the 2 scans, sagittal rotation. This is also the motion with the widest range; the error of the method is relatively smaller in these measurements. The aims of ADR are for the implants to

TABLE 4. The relative measured movement between the loose component and the vertebra

\begin{tabular}{cccccccc}
\hline Case & \multicolumn{3}{c}{ Rotation $\left({ }^{\circ}\right)$} & & \multicolumn{3}{c}{ Translation $(\mathrm{mm})$} \\
\cline { 2 - 4 } \cline { 6 - 8 } No. & Coronal & Sagittal & Transaxial & & Coronal & Sagittal & Transaxial \\
\hline 1 & 1.1 & 0.8 & 0.7 & & 0.3 & 0.4 & 0.3 \\
\hline 2 & 0.9 & 1.6 & 0.5 & & 0.4 & 0.4 & 0.6 \\
\hline 3 & 0.7 & 3.4 & 0.4 & & 0.2 & 0.2 & 0.3 \\
\hline
\end{tabular}


TABLE 5. Results of the validation between 2 observers

\begin{tabular}{llll}
\hline \multirow{2}{*}{ Motion } & \multicolumn{3}{c}{ 2 Observers $(\mathrm{n}=38)$} \\
\cline { 2 - 4 } & ICC & Repeatability & SEM \\
\hline Rotation & & & \\
\hline Coronal & 0.95 & $1.05^{\circ}$ & 0.38 \\
\hline Sagittal & 0.99 & $1.30^{\circ}$ & 0.47 \\
\hline Transaxial & 0.96 & $0.93^{\circ}$ & 0.34 \\
\hline Translation & & & \\
\hline Coronal & 0.30 & $0.77 \mathrm{~mm}$ & 0.29 \\
\hline Sagittal & 0.84 & $1.29 \mathrm{~mm}$ & 0.46 \\
\hline Transaxial & 0.66 & $1.78 \mathrm{~mm}$ & 0.64 \\
\hline
\end{tabular}

SEM $=$ standard error of measurement.

maintain cervical mobility and for the components of the ADR to achieve sufficient stability relative to the adjacent vertebrae. ROM in this study was significantly less at C6-7 than at C5-6. The ROM at C4-5 was almost the same as for C5-6, but a statistically significant difference could not be established in comparison with C6-7, probably because of the small sample size in the C4-5 group. There may be several conceivable factors influencing these variations, but, most likely, they are explained by differences in preoperative segment mobility due to varying degrees of disc degeneration. As no preoperative CT scans were available, no study of the correlation between pre- and postoperative ROM was performed. A higher degree of degeneration in the segment could, theoretically, lead to the need for a greater extent of bone removal from endplates and uncovertebral joints to achieve sufficient decompression. Such interaction might enhance the development of $\mathrm{HO}$ with inhibited ROM in that segment. On the other hand, a larger ROM, as seen in the C4-5 and C5-6 segments, might instead cause higher stress on the surface of fixation between the implant and the vertebra, leading to instability and migration of the ADR. All of the unstable discs were found at the C5-6 level, which could strengthen this theory. Migration in a worst-case scenario could cause serious and irreversible neurological damage. ${ }^{35}$ None of the patients in this study had any neurological impairment, and the decision to undergo revision surgery was due to the results of this motion analysis, showing highly instable implants, in combination with increased neck pain. A previously published motion study of the same artificial disc reported migration in 6 of 55 patients $(11 \%),{ }^{10}$ although evaluations were done with plain radiographs. Other previous radiographic studies on other artificial discs have not reported similar figures concerning loosening or migration to the same extent. ${ }^{2,15,24,25}$ This can be explained by postulating that no such problems actually existed, or that the imaging technique was not of sufficient accuracy or resolution to detect it. Furthermore, if motion is measured only in parts of the prosthesis and not relative to the bone, vital information about implant stability is lost. We compared plain radiographs, obtained prior to secondary surgery, to the 3D CT analysis concerning instability of all the patients who underwent reoperation. Motion within the implants could be detected, but instability relative to the vertebra could not be established in flexion and extension on plain radiographs. The definition of an unstable or loose prosthesis is also somewhat unclear since there might always be some micromotion between implants and bone. We defined instability or loosening as a detectable motion between bone and prosthesis when comparing the 2 scans. It can be argued that the measured motion between implants and adjacent vertebrae showed measured values close to the limit of the accuracy of the method. However, the combination of these findings and increasing neck pain in these 3 patients led to the decision for revision surgery, where the radiological findings were confirmed. In another patient, we found radiographic osteolysis around the spikes of the apical part of the prosthesis, without any detectable motion relative to adjacent bone (Fig. 4). This is an interesting finding for which there may be various theories. First, there is a possibility that the prosthesis was unstable but that the motion was so small that it was not detectable with this method. Second, the provocation was inadequate so that the prosthetic part did not move in that specific rotation. In that case, this is a finding of a possible asymptomatic, early loosening. However, primary osteolysis is also possible and raises the question of what comes first, osteolysis or loosening? One can speculate that primary osteolysis might be caused by wear associated with microparticles, but support for this cannot be shown in this study. The calculated $95 \%$ CI for loosening shows a wide range in this study and should be interpreted with caution since the sample size is relatively small. The problem with formation of heterotopic bone may cause reduced mobility and even ankylosis. The influence of NSAIDs on bone formation and ingrowth into HA coating is controversial and may, if there is an effect, be dependent on dosage. ${ }^{7,11,36,39}$ The patients in this study were all given low doses of diclofenac for 10 days, which may have decreased $\mathrm{HO}$ but also ingrowth of bone to the HA-coated titanium endplates. We cannot determine whether the NSAIDs in this study had any effect on $\mathrm{HO}$, and these data have to be compared with data from other studies. The frequencies of $\mathrm{HO}$ in other studies vary, and there does not seem to be a clear correlation to patient outcome. Suchomel et al. found significant $\mathrm{HO}$ in $45 \%$ and ankylosis in $18 \%$ in a cohort of 50 patients in a 4-year follow-up after treatment with the ProDisc-C. ${ }^{29} \mathrm{Tu}$ et al. have performed studies on $\mathrm{HO}$ with CT on patients treated with the Bryan artificial disc. They did not find the same high incidence of $\mathrm{HO}$ and concluded that appropriate carpentry is an important factor to avoid development of $\mathrm{HO}{ }^{33,34} \mathrm{Wu}$ et al. found a significantly higher incidence of $\mathrm{HO}$ in 2-level surgeries than in 1-level surgeries, $75 \%$ and $40 \%$, respectively. ${ }^{38}$ In a meta-analysis published by Chen et al., no clear association between the formation of $\mathrm{HO}$ and clinical outcome was found. ${ }^{3}$ The McAfee scale with 5 gradations of $\mathrm{HO}$ has been used in many studies and has been validated with regard to intraobserver reliability. ${ }^{13}$ We did not further analyze or grade the presence of heterotopic bone, but the motion analysis revealed that 2 prostheses were totally ankylotic and 3 were inhibited in motion due to heterotopic bone formation. Theoretically, an ADR that loses motion due to $\mathrm{HO}$ will function in the same way as a fusion. However, knowledge about loose, and in the longer term possibly migrat- 
ing ADR devices, is very limited. Cunningham et al. studied osseointegration of 29 implants in both the cervical and the lumbar spine in relation to placement. They found less ingrowth of bone in poorly placed implants, although the difference was not statistically significant. ${ }^{4}$ In another study of interest relating to this issue, Palissery et al. investigated the stress patterns in the vertebral body in correlation to implant size. They found, not surprisingly, that a smaller implant footprint resulted in a higher load and stress to the endplates in lumbar spine, but it can be assumed that the same conditions prevail in the cervical spine. ${ }^{18}$ In our study, only 1 type of device was evaluated, but it would be desirable to compare stability between different designs and concepts, as the method of fixation might influence stability. ${ }^{5} \mathrm{~A}$ weakness of this study is that preoperative data were not available. Such data would have been desirable, especially when interpreting differences in postoperative motion between different cervical levels; these data can possibly be provided in future studies. Another weakness is the long range in time between surgery and CT scanning, as both prevalence of $\mathrm{HO}$ and implant instability, theoretically, might increase with time. The small sample size is also a limitation, and associations between radiographic pathology and clinical outcome cannot be made. Funding from the manufacturer of the implant was received for this study but the support was totally unrestricted, and the company had no influence in the design of the study or in analysis of the data.

\section{Conclusions}

The majority of the Discover artificial discs in this study maintained cervical mobility after implantation, and the discs remained stable, with proper attachment. However, $8 \%$ of the Discover discs in this study exhibited clear signs of instability, which was confirmed later by revision surgery. Thirteen percent of the treated levels were ankylotic or showed clearly inhibited motion due to HO. All of the patients with confirmed instability underwent revision surgery because of increased neck pain, while none of the patients with ankylosis or inhibited motion needed revision surgery. This study indicates also that the development of instability and nonfixation poses a greater risk of revision surgery than does the development of inhibited motion due to ankylosis or HO.

\section{Acknowledgments}

We thank Elisabeth Berg for statistical advice, Michael Zeleznik for important contributions to the manuscript, and the staff at Aleris Radiological Clinic, Löwenströmska Sjukhuset, for performing all CT scans.

\section{References}

1. Axelsson P, Karlsson BS: Standardized provocation of lumbar spine mobility: three methods compared by radiostereometric analysis. Spine (Phila Pa 1976) 30:792-797, 2005

2. Burkus JK, Haid RW, Traynelis VC, Mummaneni PV: Longterm clinical and radiographic outcomes of cervical disc replacement with the Prestige disc: results from a prospective randomized controlled clinical trial. J Neurosurg Spine 13:308-318, 2010

3. Chen J, Wang X, Bai W, Shen X, Yuan W: Prevalence of heterotopic ossification after cervical total disc arthroplasty: a meta-analysis. Eur Spine J 21:674-680, 2012

4. Cunningham BW, Hu N, Zorn CM, McAfee PC: Bioactive titanium calcium phosphate coating for disc arthroplasty: analysis of 58 vertebral end plates after 6- to 12-month implantation. Spine J 9:836-845, 2009

5. Cunningham BW, Hu N, Zorn CM, McAfee PC: Comparative fixation methods of cervical disc arthroplasty versus conventional methods of anterior cervical arthrodesis: serration, teeth, keels, or screws? J Neurosurg Spine 12:214-220, 2010

6. Dorey F, Nasser S, Amstutz H: The need for confidence intervals in the presentation of orthopaedic data. J Bone Joint Surg Am 75:1844-1852, 1993

7. Jacobsson SA, Djerf K, Ivarsson I, Wahlström O: Effect of diclofenac on fixation of hydroxyapatite-coated implants. An experimental study. J Bone Joint Surg Br 76:831-833, 1994

8. Landis JR, Koch GG: The measurement of observer agreement for categorical data. Biometrics 33:159-174, 1977

9. Leivseth G, Kolstad F, Nygaard OP, Zoega B, Frobin W, Brinckmann P: Comparing precision of distortion-compensated and stereophotogrammetric Roentgen analysis when monitoring fusion in the cervical spine. Eur Spine J 15:774779, 2006

10. Li J, Liang L, Ye XF, Qi M, Chen HJ, Yuan W: Cervical arthroplasty with Discover prosthesis: clinical outcomes and analysis of factors that may influence postoperative range of motion. Eur Spine J 22:2303-2309, 2013

11. Li Q, Zhang Z, Cai Z: High-dose ketorolac affects adult spinal fusion: a meta-analysis of the effect of perioperative nonsteroidal anti-inflammatory drugs on spinal fusion. Spine (Phila Pa 1976) 36:E461-E468, 2011

12. Lind B, Zoëga B, Anderson PA: A radiostereometric analysis of the Bryan Cervical Disc prosthesis. Spine 32:885-891, 2007

13. McAfee PC, Cunningham BW, Devine J, Williams E, Yu-Yahiro J: Classification of heterotopic ossification (HO) in artificial disk replacement. J Spinal Disord Tech 16:384-389, 2003

14. McDonald CP, Bachison CC, Chang V, Bartol SW, Bey MJ: Three-dimensional dynamic in vivo motion of the cervical spine: assessment of measurement accuracy and preliminary findings. Spine J 10:497-504, 2010

15. Mummaneni PV, Burkus JK, Haid RW, Traynelis VC, Zdeblick TA: Clinical and radiographic analysis of cervical disc arthroplasty compared with allograft fusion: a randomized controlled clinical trial. J Neurosurg Spine 6:198-209, 2007

16. Noz ME, Maguire GQ Jr, Zeleznik MP, Kramer EL, Mahmoud F, Crafoord J: A versatile functional-anatomic image fusion method for volume data sets. J Med Syst 25:297-307, 2001

17. Olivecrona L, Olivecrona H, Weidenhielm L, Noz ME, Maguire GQ Jr, Zeleznik MP: Model studies on acetabular component migration in total hip arthroplasty using CT and a semiautomated program for volume merging. Acta Radiol 44:419-429, 2003

18. Palissery V, Mulholland RC, McNally DS: The implications of stress patterns in the vertebral body under axial support of an artificial implant. Med Eng Phys 31:833-837, 2009

19. Panjabi M, Chang D, Dvorák J: An analysis of errors in kinematic parameters associated with in vivo functional radiographs. Spine (Phila Pa 1976) 17:200-205, 1992

20. Park DK, Lin EL, Phillips FM: Index and adjacent level kinematics after cervical disc replacement and anterior fusion: in vivo quantitative radiographic analysis. Spine (Phila Pa 1976) 36:721-730, 2011

21. Park SA, Fayyazi AH, Ordway NR, Sun MH, Fredrickson $\mathrm{BE}$, Yuan HA: Correlation of radiostereometric measured cervical range of motion with clinical radiographic findings after anterior cervical discectomy and fusion. Spine (Phila Pa 1976) 34:680-686, 2009 
22. Park SA, Ordway NR, Fayyazi AH, Fredrickson BE, Yuan HA: Comparison of Cobb technique, quantitative motion analysis, and radiostereometric analysis in measurement of segmental range of motions after lumbar total disc arthroplasty. J Spinal Disord Tech 22:602-609, 2009

23. Pickett GE, Rouleau JP, Duggal N: Kinematic analysis of the cervical spine following implantation of an artificial cervical disc. Spine (Phila Pa 1976) 30:1949-1954, 2005

24. Pickett GE, Sekhon LH, Sears WR, Duggal N: Complications with cervical arthroplasty. J Neurosurg Spine 4:98-105, 2006

25. Quan GM, Vital JM, Hansen S, Pointillart V: Eight-year clinical and radiological follow-up of the Bryan cervical disc arthroplasty. Spine (Phila Pa 1976) 36:639-646, 2011

26. Ryd L, Yuan X, Löfgren H: Methods for determining the accuracy of radiostereometric analysis (RSA). Acta Orthop Scand 71:403-408, 2000

27. Selvik G, Alberius P, Aronson AS: A roentgen stereophotogrammetric system. Construction, calibration and technical accuracy. Acta Radiol Diagn (Stockh) 24:343-352, 1983

28. Shaffer WO, Spratt KF, Weinstein J, Lehmann TR, Goel V: 1990 Volvo Award in clinical sciences. The consistency and accuracy of roentgenograms for measuring sagittal translation in the lumbar vertebral motion segment. An experimental model. Spine (Phila Pa 1976) 15:741-750, 1990

29. Suchomel P, Jurák L, Benes V III, Brabec R, Bradác O, Elgawhary S: Clinical results and development of heterotopic ossification in total cervical disc replacement during a 4-year follow-up. Eur Spine J 19:307-315, 2010

30. Svedmark P, Lundh F, Németh G, Noz ME, Maguire GQ $\mathrm{Jr}$, Zeleznik MP, et al: Motion analysis of total cervical disc replacements using computed tomography: preliminary experience with nine patients and a model. Acta Radiol 52:11281137, 2011

31. Svedmark P, Tullberg T, Noz ME, Maguire GQ Jr, Zeleznik MP, Weidenhielm L, et al: Three-dimensional movements of the lumbar spine facet joints and segmental movements: in vivo examinations of normal subjects with a new non-invasive method. Eur Spine J 21:599-605, 2012

32. Svedmark P, Weidenhielm L, Nemeth G, Tullberg T, Noz ME, Maguire GQ Jr, et al: Model studies on segmental movement in lumbar spine using a semi-automated program for volume fusion. Comput Aided Surg 13:14-22, 2008

33. Tu TH, Wu JC, Huang WC, Guo WY, Wu CL, Shih YH, et al: Heterotopic ossification after cervical total disc replacement: determination by $\mathrm{CT}$ and effects on clinical outcomes. J Neurosurg Spine 14:457-465, 2011
34. Tu TH, Wu JC, Huang WC, Wu CL, Ko CC, Cheng H: The effects of carpentry on heterotopic ossification and mobility in cervical arthroplasty: determination by computed tomography with a minimum 2-year follow-up. Clinical article. J Neurosurg Spine 16:601-609, 2012

35. Viezens L, Schaefer C, Beyerlein J, Thietje R, Hansen-Algenstaedt N: An incomplete paraplegia following the dislocation of an artificial cervical total disc replacement. J Neurosurg Spine 18:255-259, 2013

36. Vuolteenaho K, Moilanen T, Moilanen E: Non-steroidal antiinflammatory drugs, cyclooxygenase- 2 and the bone healing process. Basic Clin Pharmacol Toxicol 102:10-14, 2008

37. Watanabe $S$, Inoue $N$, Yamaguchi T, Hirano Y, Espinoza Orias AA, Nishida S, et al: Three-dimensional kinematic analysis of the cervical spine after anterior cervical decompression and fusion at an adjacent level: a preliminary report. Eur Spine J 21:946-955, 2012

38. Wu JC, Huang WC, Tsai HW, Ko CC, Fay LY, Tu TH, et al: Differences between 1- and 2-level cervical arthroplasty: more heterotopic ossification in 2-level disc replacement. Clinical article. J Neurosurg Spine 16:594-600, 2012

39. Zeckey C, Hildebrand F, Frink M, Krettek C: Heterotopic ossifications following implant surgery-epidemiology, therapeutical approaches and current concepts. Semin Immunopathol 33:273-286, 2011

40. Zhao X, Wu ZX, Han BJ, Yan YB, Zhang Y, Lei W: Threedimensional analysis of cervical spine segmental motion in rotation. Arch Med Sci 9:515-520, 2013

\section{Author Contributions}

Conception and design: Skeppholm, Olerud. Acquisition of data: Skeppholm, Svedmark, Noz, Maguire. Analysis and interpretation of data: Skeppholm, Svedmark, Noz, Maguire, Olivecrona. Drafting the article: Skeppholm. Critically revising the article: Svedmark, Noz, Maguire, Olivecrona, Olerud. Reviewed submitted version of manuscript: Svedmark, Noz, Maguire, Olivecrona, Olerud. Approved the final version of the manuscript on behalf of all authors: Skeppholm. Statistical analysis: Skeppholm. Administrative/technical/material support: Olivecrona. Study supervision: Olivecrona, Olerud.

\section{Correspondence}

Martin Skeppholm, Stockholm Spine Center, Löwenströmska Sjukhuset, 19489 Upplands Väsby, Sweden. email: martin. skeppholm@spinecenter.se. 